\title{
OS ANNALES ALÉM DA HISTORIOGRAFIA
}

\section{ARTIGO ORIGINAL}

DENDASCK, Carla Viana ${ }^{1}$

DENDASCK, Carla Viana. Os Annales Além Da Historiografia. Revista Científica Multidisciplinar Núcleo do Conhecimento. Ano 03, Ed. 12, Vol. 07, pp. 31-39 Dezembro de 2018. ISSN:2448-0959

\section{RESUMO}

A escola dos Annales (1929-1989) foi apontada por Peter Burke como "a revolução francesa da historiografia". Assim, dentro das elucidações de Peter Burke, este artigo tem como objetivo realizar uma reflexão sobre uma revista que foi capaz de reunir grandes mentes e se tornar um fenômeno que impulsionou não apenas um movimento acadêmico generalizado, mas também, impulsionou uma nova forma de fazer história, influenciando direta ou indiretamente as demais ciências que se sentiram de alguma forma enriquecidas, e/ou inspirada com os Annales, ultrapassando as fronteiras da Europa, e, servindo de inspiração e (re) direcionamento até os dias atuais. Como metodologia, foi realizada uma pesquisa exploratória, com abordagem qualitativa partindo da obra de Peter Burke, e perpassando por algumas influências que os Annales foram exercendo até ser considerada uma escola. A justificativa para o desenvolvimento deste estudo reflexivo está na necessidade de construir uma memória que além de servir como reconhecimento da construção da história e, das demais ciências, também pode servir como base de lições de ações que impulsionam movimentos, capazes de quebrar obstáculos, e, mudar os caminhos de pensamento

\footnotetext{
${ }^{1}$ Teóloga, Doutora em psicanálise clínica. Atua há 15 anos com metodologia científica ( método de pesquisa) na orientação de produção científica de mestrandos e doutorandos. Especialista em pesquisas de mercado e pesquisas voltadas a área da saúde.
} 
de uma sociedade. Na conclusiva, observa-se que os Annales através de suas mentes transcenderam o contexto da historiografia.

Palavras-Chaves: Annales, Historiografia, Mentalidades.

\section{INTRODUÇÃO}

Dentre as lições que tenho aprendido no decorrer de minha vida, uma em especial, trouxe um enriquecimento que me servirá para o restante dos meus dias, e, que deverei a escola dos Annales, e, em especial ao professor Gerson Leite de Moraes por nos mostrar esse presente. Certamente essa lição foi responsável por deixar de usar a terceira pessoa neste introito, e, me apropriar do texto com uma pessoalidade que antigamente não era possível nas construções de textos acadêmicos. Também foi, através destas lições que se decidiu fazer um breve resumo de nosso recorte (os Annales), para que o leitor, caso não conheça, possa introduzir-se, mesmo de forma breve, a compreender os Annales, e, para àqueles que já conhecem, possam relembrar e se inspirar neste movimento.

Peter Burke (1937), foi um dos historiadores ingleses mais prestigiados a nível global, em especial no Brasil. De acordo com Barros (2011) além de suas obras se destacarem por serem interdisciplinares, manteve fortes relações com a acadêmica brasileira, especialmente em sua atuação como professor visitante da Universidade de São Paulo.

Impulsionado pelo seu interesse pela história do saber, e construção do conhecimento, Peter Burker, transitou por várias linhas de pensamentos partindo desde 1500, fazendo uma construção histórica dos principais fenômenos e movimentos responsáveis pelo saber, especialmente no contexto do ocidente (QUELER, 2014), desfrutando-se das possibilidades implementadas anteriormente pelos Annales.

Em 1990, publicou a obra "A escola dos Annales 1929-1989: A revolução francesa da historiografia", que precedeu a "Revolução historiográfica Francesa". Acredita-se que 
em suas investigações sobre a construção do conhecimento numa perspectiva historiográfica dentro do contexto francês, o autor tenha se deparado com a grandiosidade da influencia dos Annales, e, por isso, tenha dedicado uma obra especialmente a detalhar este movimento, iniciado com a criação de uma revista.

Assim, cabe dedicar uma parte deste estudo, mesmo que de forma breve, fazer um breve panorama dos Annales, a partir de Peter Burke, para que seja compreensível o posicionamento de que esta foi capaz de transcender a história, como aludido anteriormente.

\section{OS ANNALES}

Os Annales foi inicialmente uma revista que se iniciou através das inquietações de March Bloch e Lucien Fevre quanto a história conhecida e ensinada possui apenas traços de positivosmo, sempre à luz da retórica dos vencedores. Ambos professores universitários, criaram a revista em 1929, e contou com outros pesquisadores para que pudesse alcançar o sucesso e influencia até ser considerada uma escola.

De acordo com Burke (2010):

O núcleo central do grupo é formado por Lucien Febvre, Marc Bloch, Fernand Braudel, Geroge Duby, Jacques Le Goff e Emmanuel Le Rou Ladurie. Próximos desses centros estão Ernest Labrouse, Pierre Vilar, Maurice Agulhon e Michel Vovelle, quantro importantes historiadores cujo compromisso com uma visão marxista da história- particularmente forte no caso de Vilar- coloca-os fora desse núcleo. Aquém, ou além dessa fronteira estão Roland Mousnier e Michel Foucault (pp. 11-12).

Nota-se que em sua composição central os Annales detinham um conhecimento multidisciplinar, o que impulsionou a produção cultural interdisciplinar durante 60 anos, sendo uma de suas justificativas de sua abrangência, além disso, as revistas e jornais entre os séculos XVIII ao XX, eram essenciais no processo de formação pública, onde 
a voz de um, geralmente representava a voz de um grupo, que iam se formando e posicionamento ao redor destes veículos de comunicação.

A junção então da representatividade das revistas e jornais no período de 1929-1989, junto com a interdisciplinaridade que os artigos eram tratados, fez com que grande parcela da sociedade se sentisse representada à voz dos Annales, e daí a influencia de se fazer história dentro de uma perspectiva nova, à luz da voz de todos, ou pelo menos, abrindo espaço para que fosse possível investigar a "voz de todos".

Além disso, os Annales vão atuar dentro de um contexto em ebulição, com seu início no final da Primeira Guerra Mundial, percorrendo a Segunda Guerra Mundial, a quebra de barreiras econômicas mundiais, a globalização, e ainda, a evolução tecnológica, criação da internet, e uso de técnicas científicas dentro da manipulação da vida. Ou seja, uma efervescência, não apenas no contexto europeu, mas mundial.

Nesses 60 anos de existência, Burke (2010) apontou 3 gerações, que atuaram em um processo cíclico comum, e que pode servir como ilustração de um cenário o qual "os rebeldes de hoje serão o establishment[2] de amanhã”, momento este que os Annales passam a ser apontados como uma Escola.

Cada geração foi marcada por características específicas, que estavam diretamente relacionados aos intelectuais de épocas diferentes. Quando se denota "épocas diferentes", quer-se justamente evidenciar que apesar de existir por 60 anos, o que pode aparentar no primeiro momento uma certa "estabilidade", observa-se que os 60 anos em que os Annales se consagraram, as mudanças socioeconômicas, foram intensamente desbruptivas.

A terceira e ultima geração dos Annales representaram suas influências das tendências das dinâmicas sociais, e das outras áreas da ciência, ao implementar uma administração descentralizada justamente em que as ciências administrativas passavam a defender (PIMENTA, 1994). Além disso, foi a primeira geração a incluir mulheres, obedecendo uma pressão social devido aos movimentos de igualdade entre gêneros. 
Também, obedecendo as tendências de intercâmbios, e da própria globalização intercultural (aquela anteriormente já mencionada por Le Goff).

Muitos de seus membros viveram um ano ou mais nos Estados Unidos, em Princeton, Ithaca, Madison ou San Diego. Diferentemente de Braudel, falam e escrevem em inglês. Por diferentes caminhos, tentaram fazer uma síntese entre a tradição dos Annales e as tendências intelectuais americanas - como a psico-história, a nova história econômica, a história da cultura popualr, antropologia simbólica etc (BURKE, 2010, p.90).

De acordo com Burke (2010), alguns historiadores ainda se desdobram a relatar a continuidade da escola dos Annales em seus estudos, dentre eles o próprio Le Goff. No entanto, deve-se observar que, embora Peter Burke, tenha apontado três gerações altamente influentes entre os anos de 1929 a 1989, a história dos Annales ainda continua na quarta geração, até os dias atuais, talvez não tão influente quanto os primeiros 60 anos, mas ainda, fazendo uma parte importante da sociedade. Suas discussões e publicações podem ser encontradas através do website: http://annales.ehess.fr.

A ultima edição encontrada, datada de outubro a dezembro de 2016, traz em seu escopo matérias como: Economia da África Contemporânea, História de Marrocos, e, Sociologia, criação e ação, continuando assim, a comprovar sua inclinação para tratar dentro da historiografia diversos assuntos que influenciam direta ou indiretamente os cenários contemporâneos.

\section{AS NOVAS POSSIBILIDADES - TRANSCENDENDO A HISTÓRIA}

Dentro do que até aqui fora demonstrado, o cenário mundial, a equipe multidisciplinar, a interdisciplinaridade dos materiais publicados, impulsionaram a influencia dos Annales que passaram a ser visualizados como um movimento, e, dentro destas alusões, também como um fenômeno. Um fenômeno que se estendeu a nível mundial, e transcendeu as barreiras da história. 
Não é preciso ir muito longe, para compreender que as aplicações dos Annales e suas influencias transcenderam a historiografia, nota-se isso, através de sua própria representatividade no campo político de sua época.

De acordo com Burke (2010):

Os Annales começaram como uma revista de seita herética. "É necessário ser herético", declarou Febvre em sua aula inaugural, Oportet haereses esse (Febvre 1953, p.16). Depois da Guerra, contudo, a revista transformou-se no órgão oficial de uma igreja ortodoxa. Sob a liderança de Febvre, os revolucionários intelectuais souberam conquistar o establishment histórico francês. O herdeiro desse poder seria Fernand Braudel.

Além disso, as inclinações a outras áreas, dentre elas antropologia, psicologia, ciências sociais, ciências econômicas, além do próprio nascimento da história quantitativa, influenciada pela geografia.

Quanto a história quantitativa, Burke (2010) alude que:

Dessas tendências $^{[3]}$, a mais importante, de mais ou menos 1950 a 1970, ou mesmo mais, foi certamente o nascimento da história quantitativa. Esta "revolução quantitativa, como chamada, foi o primeiro sentida no campo econômico, em particular na história dos preços. Da economia espraiou-se para a história social, especialmente para a história populacional. Por fim, na terceira geração ..... a nova tendência invadiu a história cultural- a história da religião e a história das mentalidades (pp. 73-74).

Claro que as tendências apontadas por Burke, na realidade serviram como influências, e, que posteriormente foram incorporadas por outras ciências como sendo reconhecidamente fundamentais, não apenas para construção das bases das próprias ciências, mas para compreensão e desenvolvimento de suas matérias, atuando então numa confluência de saberes. 
A exemplo disso, podemos citar o próprio Le Goff (1990), em sua obra: História e Memória, a aplicação é fundamental para diversas áreas do conhecimento, como por exemplo: educação, antropologia, psicologia, psiquiatria, administração, ciências sociais, dentre outras, sendo apontada como uma obra de referencia por muitos estudiosos, como por exemplo Meneses (1992), pesquisador atuante no campo das ciências sociais e na educação.

O próprio Burke (2010) reconhece a atuação dos Annales além das fronteiras, exercendo influencia internacional, no entanto, o que se defende neste estudo com maior enfoque, é a influencia dos Annales além dos muros da historiografia, mas da capacidade de repensar as ciências de uma forma diferente, além de aceitar a interdisciplinaridade possível através de uma escola que se dedicou a fazer uma nova forma de construção do conhecimento, reconhecer que a própria história, faz parte da essência de qualquer ciência que queira trabalhar com particularidade de eficiência em sua colocações.

É claro, que se reconhece que a Escola dos Annales, atuando como escola francesa não foi a única a existir e ter influência nas demais ciências, outras por exemplo, a italiana , ou a alemã ( especialmente a prussiana), tenham sido tão importante quanto, porém, talvez em nossa percepção, as construções dentro do conhecimento e forma de fazer ciências através dos ensinos dos Annales ( da escola francesa) estejam diretamente ligadas as caravanas acadêmicas francesas, que fizeram parte da Universidade de São Paulo, uma das academias responsáveis por implementar nossa base conhecida de ciência, que por muito tempo exerceu influencia dentro desta, inclusive com aulas realizadas exclusivamente em francês, com professores que vinham em sua grande maioria da França para lecionar um período, como os irmãos Bastide , Strauss, além de outros que não eram franceses, e, que de certa forma eram influenciados por estes no Brasil, como o próprio Peter Burke.

\section{CONSIDERAÇÕES FINAIS}

Não há como construir um conhecimento nos dias atuais, sem recorrer a base da historiografia. No caso do contexto brasileiro, o conhecimento e a forma de construir 
esse conhecimento foi influenciado diretamente pela academia francesa, colocando a escola do Annales em evidencia dentro de nossa compreensão.

Uma vez que se reconhece, que a base de conhecimento brasileiro advinda pelas caravanas francesas que faziam parte da Universidade de São Paulo, primeira universidade do Brasil com visualização internacional, reconhece-se que não é absurdo de nossa parte, a afirmação que os Annales foram responsáveis por transcender o campo da historiografia, e influenciar muitas outras ciências, em especial a antropologia, sociologia, psicologia, educação, economia, administração, dentre outras, que passaram a considerar a importância da perspectiva histórica dentro de suas concepções, composições e proposições.

Além disso, há matérias da própria historiografia, como por exemplo: a cultura, memória, mente, história da civilização, da moeda, dentre outras, que passaram a ser incorporadas em suas integras pelas demais ciências, inclusive com seus autores, que por sua vez, levam a historiografia, e consequentemente a escola dos Annales , a transcender seus muros.

\section{REFERÊNCIAS}

BURKE, Peter. A escola dos Annales (1929-1989): a revolução francesa da historiografia; Tradução Nilo Odália. 2 ed. São Paulo: Editora da Unesp, 2010

BARROS, José D’Assunção. Peter Burke: trajetória de um historiador. Rev. História Unisinos. 15(1):31-39, Janeiro/Abril 2011

LE GOFF, Jacques, 1924.s[:- História e memória ; tradução Bernardo Leitão ... [et al.] - Campinas, SP Editora da UNICAMP, 1990, p.423

MENESES, Ulpiano T. Bezerra. A História, Cativa da Memória? Para um Mapeamento da Memória no Campo das Ciências Sociais. Rev. Inst. Est. Bras, SP, 34: 9-24. 1992 
PIMENTA, Carlos César Pimenta. Aspectos recentes da organização e das políticas de modernização da função administrativa pública federal. RAP RIO DE JANEIRO 28(2), IH 7. ABR./nIN. 1994

REVUE ANNALES. Annales: Historie, Sciences Sociales. Encontrado em: http://annales.ehess.fr acesso em novembro de 2017.

QUELER, Jefferson José. Resenha: BURKE, Peter. Uma história social do conhecimento: II: da Enciclopédia à Wikipédia. Tradução Denise Bottmann. Rio de Janeiro: Zahar, 2012. 414 p. in: Horizontes Antropológicos, Porto Alegre, ano 20, n. 42, p. 395-398, jul./dez. 2014

1. tradução estabilizadores. No caso dos Annales, se refere aos intelectuais que posteriormente seriam responsáveis por moderar diversos assuntos. Como será observado na sequencia deste estudo, à luz do próprio Burke.

2. Aqui também é possível rever os impactos da escola dos Annales.

Enviado: Dezembro, 2018

Aprovado: Dezembro, 2018 